\title{
Yttrium-90 Polycarbonate Brachytherapy Plaque
}

National Cancer Institute

\section{Source}

National Cancer Institute. Yttrium-90 Polycarbonate Brachytherapy Plaque. NCI

Thesaurus. Code C80739.

A polycarbonate-based semicylindrical plaque impregnated with yttrium $Y 90$ with radioisotopic and antineoplastic activities. An yttrium-90 polycarbonate brachytherapy plaque may be applied to a tumor site with a special brachytherapy applicator for a predetermined interval of time, selectively delivering a cytotoxic dose of beta-emitting yttrium $Y 90$. 